\title{
Tribal Ethos Favours Self-Transcendence, Within the Tribe
}

\author{
Alfredo Behrens \\ behrens@usal.es | Global MBA, Universidad de Salamanca, Spain and FIA Business School, São Paulo, \\ Brazil

\section{Letter from Academia}

\begin{abstract}
Where there is little trust, can there be self-transcendence? Can one strive for openness as well as closeness between tribes? Preference to trust own clan members is much higher among Mediterranean peoples than among Germanic ones. In both Germanic and Mediterranean clusters, trusting behaviours follow culturally determined kinship patterns that are slow to change, so much so that the different Mediterranean and Germanic trust patterns still show between Latin America and the USA. Germanic managerial techniques rest on Germanic trusting behaviours that are relatively lacking in the Mediterranean cluster, among whom Germanic managerial techniques lose efficacy and self-transcendence might be a riskier path to take. Clan-friendly management among Mediterranean peoples, including rewards more readily focused on needs, teamwork and citizenship behaviour, require less controls, bringing about faster alignment and more agile organizations. These reflections are relevant to manage North African migrants into Europe, as they are to manage Latin Americans into the USA.
\end{abstract}

Keywords. Clans; Trust; Openness; Closeness; Christians; Muslims.

Cite paper as: Behrens, A., (2020). Tribal Ethos Favours Self-Transcendence, Within the Tribe - Letter from Academia, Journal of Innovation Management, www.open-jim.org, 8(1), 6-12. 


\section{Introduction}

This article follows an interesting editorial conversation (Mention et al, 2016) and a follow-up by Venter (2017), on the subject of openness and closeness, and variations on the Maslow model extended to self-transcendence, as also appears in the work of Barrett (2014).

The focus here is on the determinants of the workings of generalized trust among European countries and their cultural heirs in the New World (Behrens, 2009) and among Muslims (Majeed, 2017).

The aim towards closeness during the international expansion of corporations leads to the marked preference for hiring in the host country among those whose mindset is closest to those of headquarters, such as English-speaking professionals. However, this strategy amounts to hiring within the "Chinese comprador class" (Behrens, Singh \& Bhandarker, 2016). Those professionals are in short supply, pricier and are generally less attuned to the majority in the local market

Openness, on the other hand, would lead managers to favor diversity when building management teams, if lack of trust does not get in the way. However, among the many values that shape attitudes to collaborative work in host emerging markets and southern European ones, generalized trust falls short (Inglehart et al, 2014).

It is safe to say that everywhere collaborative work follows local accepted patterns regarding authority, trust and rewards. The same for companies born in the Mediterranean and Latin American countries: when small they are all managed in tune with local culture in ways that shape their organizational behaviour (Reay, Jaskiewicz \& Hinings, 2015). However, as they mature and grow, family firms in these countries face difficulties in the scalability of their organizational forms.

In developing countries, as well as in many countries bathed by the Mediterranean Sea, business lacks a strong base of autochthonous managerial research. The growing firms there are confronted with a relative managerial void other than the predominant one, which originated in Germanic countries and propagated through most business schools, particularly in America, after Talcott Parson's translation of Max Weber's work (1927).

The trouble is that among Mediterranean countries, and their cultural heirs in Latin America, traditional authority and ways of doing business does not seem to be a phase but a way of being; not a trait to be superseded, but one that fits the way society is organized. Yet, intellectually colonized, these societies have not come up with a managerial template fitting them. However, Germanic organizational forms and behaviours match poorly the Mediterranean culture, North and southern shores, and result in weak engagement on the part of the workforce, with the consequent waste of their productivity potential.

\section{Differences in trusting levels}

In particular, clan-based societies have specific forms of socialization that are expressed in the low level of trust given to people outside the clan. On the contrary, in cultures of more indi- 


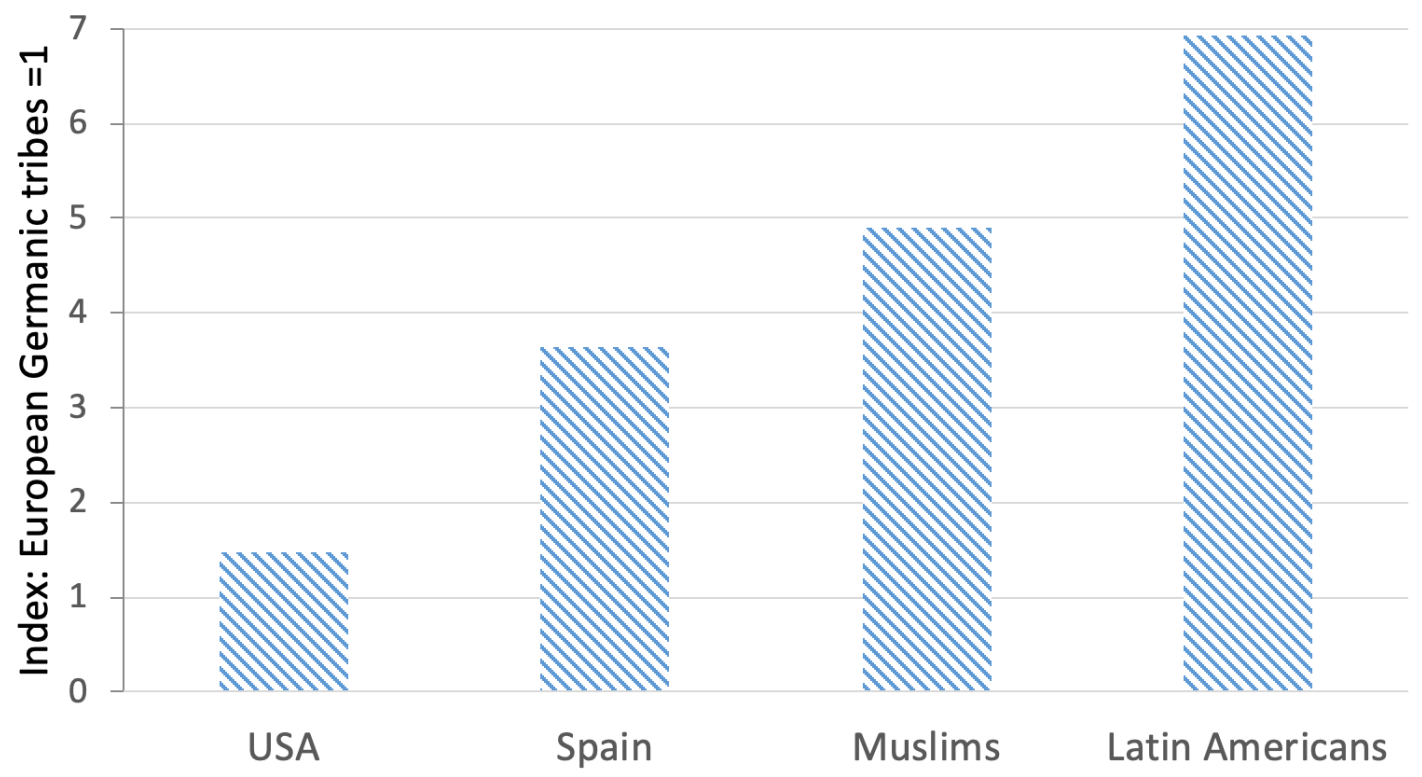

Graph 1. How many more times is trust granted to family members than to outsiders, compared to European Germanic tribes

Source: Author's own on Wave 6 of World Values Survey data. Graph 1 expresses the result of dividing the shares of replies to V102 "Completely trust the family" by V24 "Most people can be trusted". Latam reflects the average replies of peoples in Argentina, Brazil, Chile, Colombia, Ecuador, Mexico, Peru and Uruguay. Muslim reflects the average replies of peoples in Algeria, Egypt, Jordan, Lebanon, Libya, Morocco, Palestine, Tunisia and Turkey. Germanic reflects the average replies of peoples in Germany, Netherlands and Sweden. Because of the salience of the USA in producing management techniques, for purposes of illustration, respondents from that country were detached from the Germanic cluster.

vidualistic regions of northern Europe and America, people develop more extended high levels of trust, with important expressions in organizational behaviour, as openness, with the faster integration of outsiders into work teams allowing for greater specialization and mobility, both greatly contributing to high productivity among Germanic cultures. However, the nature of the trust, which underpins Germanic organizational preference, is relatively lacking in Mediterranean cultures, which emphasizes closeness.

In Southern Europe, in much of Latin America, as well as in Muslim countries, widespread trust is lower than in Germanic countries and the USA (Olivera, 2015; Inglehart et al, 2014).

Comparing how much greater is the level of trust in the family vis-à-vis the trust granted to the general public offers an indication of how much more inward-looking, more clan-oriented, a people are when it comes to making themselves vulnerable to the other, i.e. trusting. I illustrate this in Graph 1.

Indeed, Graph 1 points out how much more inclined to trust clan members than outsiders are Muslims, Latin Americans, and the Spanish. The figures suggest that, on average, the inclination 
to trust clan members over the rest is about two to five times higher among Mediterranean peoples than among USA-Americans or those of Germanic cultures.

This is particularly relevant to European countries with strong Muslim residents. Among the latter, there is an important orientation towards trusting clan members over the rest (Mertzanis, 2017). This undermines national social cohesion at host countries (Majeed, 2017) where it also promotes discrimination of Muslims at work (Pierné, 2018). The Muslim challenge to effective management in Europe is likely to increase because of the high influx of Muslim migrants and their initial higher fertility over time (Westoff \& Fretja, 2007).

\section{Clans, self-transcendence and management}

The continued resolution of the conflict between openness and closeness requires that clans be managed in congruence with their culture. Self-transcendence, with its optimism and altruism, is riskier where trust is low, as when one is outside of one's own culture. The European religious wars of the 17th century offer a pointed illustration of the risk of self-transcendence if one were a Catholic in a Protestant land, or vice versa. Yet, one need not go as far back. It was risky to be a Jew or a Roma in continental Europe under Hitlerism. Referring to Catholic countries by the unsavory acronym, PIIGS (BBC, 2010), or the workings which led to Brexit, or even the lack of a European Union-wide quick response to the Covid1-19 pandemic threat, are more recent expressions of the same difficulty of conceiving self-transcendence across clans when a tribal ethos predominates. The drive towards standardization, so prevalent in the mainstream business community, gives place to nit-picking regulations like determining the sugar content of jam in the European Union (Grice, 2013).

Self-transcendence, as a desirable endeavor, thrives more easily with openness and is more likely within clans. Inside clans, the acceptance of managerial ambiguity regarding goals, rewards and procedures, is possible because of the strong sense of community around which the clans are built - as well as by the intense exchange of information within the clan. Both tolerance and internal cohesion inhibit opportunistic behavior and facilitate cooperation with few objective control mechanisms. The arrangement excludes the need to formalize performance assessments, which, in any case, could hardly be managed in the absence of contractual standards. This is why the organizational forms of the clan generate less incongruity, favoring cooperation (Ouchi, 1980). This is what one sees in large and effective clan organizations in such disparate countries like Brazil and India. There, whether samba schools or dabbawalas, deliver to a high degree of exactness within clan structures, where trust and self-transcendence is high, and granted by recruitment practices based on affinities, such as provided by clans (Behrens, Singh \& Bhandarker, 2016).

Where clan attitudes prevail, clan-appropriate management styles may be the shortest, least-cost path to high performance. This would involve recruiting by internal referrals and allowing natural leaders to emerge. These are likely to be more paternalistic than would be acceptable in Germanic or Anglo-Saxon cultures (Behrens, 2010, 2018). Besides, clan-appropriate management is more likely to foster protagonism, altruism, to tolerate non-rational expressions such as religion or idealism in the workplace, and is also more likely to reward for needs as well for behaviours that 
reinforce cohesion rather than individual contribution to goals. Without trust, self-transcendence might not go very far.

In the eyes of the management advocated in non-clan cultures, with its pragmatic emphasis on procedures over relationships, and on logical and professional individualism, the clan's management will seem irrational and subjective, therefore inadequate and non-functional. However, in clan-oriented societies, where trust towards out-groups is lower, the clan's organizational form, which builds along trust clan lines, should facilitate the alignment of subordinates to their leaders and the faster integration of work teams, generating higher productivity with more joy, building on self-transcendence.

\section{Concluding remarks}

Germanic business practices might suffocate self-transcendence where it is more likely to appear: in clannish societies. There are two ways to favour the appearance to self-transcendence aims: to improve the match of management to culture and to diminish distrust between clans. I have suggested an Ouchi-based approach to management of clans, as spontaneously practiced in Brazilian samba schools or among Mumbai dabbawalas. To diminish distrust it will take greater advocacy, like the obvious stamping out of insults, i.e. PIIGS, but also finer grained attentiveness, like withholding from attempts to standardization where it might unnecessarily stifle diversity, like regulating on the sugar content of jams across Europe. Still on the issue of advocacy, one could start building less on our differences and more on what we have in common, like love of peace, generosity, fairness, and fulfillment. For instance, children stories have collected the peoples' expectations of good kings, queens and sheikhs; what made them so noble? What can we learn from those stories to put into business practice today? After all, stories shape mindsets and we might not be making the best use of them in a management style that reflects Mediterranean mindsets (Behrens and Medeiros, 2020).

\section{References}

Barrett, R. (2014) The Values-Driven Organization: Unleashing Human Potential for Performance and Profit. New York: Routledge

BBC (2010). Europe's PIGS: Country by country. http://news.bbc.co.uk/2/hi/8510603.stm. Accessed on February 6, 2020.

Behrens, A. (2009). Culture and Management in the Americas. Palo Alto: Stanford University Press.

Behrens, A. (2010). Charisma, Paternalism, and Business Leadership in Latin America. Thunderbird International Business Review. 52 (1) 21-28.

Behrens, A., Singh, P., Bhandarker, A. (2016). View from Practice: Managing Effectively in Collectivist Societies: Lessons from Samba Schools and Dabbawalas. Thunderbird International Business Review. 60(2) 137-145 
Behrens, A. (2018). Gaucho Dialogues on Leadership and Management. London: Anthem Press.

Behrens, A. and Medeiros, I. (2020). A Pig in a Poke Management. Thunderbird International Business Review. https://doi.org/10.1002/tie.22117

Grice, A. (2013) When is jam not a jam? When the EU says is should be a fruit spread. https://www.independent.co.uk/news/uk/politics/when-is-jam-not-a-jam-when-the-eu-says-it-shouldbe-a-fruit-spread-8536956.html Accessed on February 6, 2020.

Inglehart, R., C. Haerpfer, A. Moreno, C. Welzel, K. Kizilova, J. Diez-Medrano, M. Lagos, P. Norris, E. Ponarin \& B. Puranen et al. (eds.). (2014). World Values Survey: Round Six Country-Pooled Datafile 2010-2014. Madrid: JD Systems Institute.

Majeed, M. T. (2017). Economic growth and social cohesion: Evidence from the organization of Islamic conference countries. Social Indicators Research, 132(3), 1131-1144.

doi:http://dx.doi.org.lbs.idm.oclc.org/10.1007/s11205-016-1332-3

Mention, Anne-Laure \& Pinto Ferreira, João José \& Torkkeli, Marko. (2016). Revisiting Openness: A must for Society. Journal of Innovation Management. 4. 1. 10.24840/21830606_004.003_0001.

Mertzanis, C. (2017). Family ties and access to finance in an Islamic environment. Journal of International Financial Markets, Institutions and Money. Volume 48, May 2017, Pages 124

Olivera, J. (2015). Changes in inequality and generalized trust in Europe. Social Indicators Research, 124(1), 21-41. doi:http://dx.doi.org.lbs.idm.oclc.org/10.1007/s11205-014-0777-5

Ouchi, W. G. (1980). Markets, Bureaucracies, and Clans. Administrative Science Quarterly, 25(1) 129-141.

Pierné, G. (2018) Hiring discrimination, ethnic origin and employment status", International Journal of Manpower, 39(1) 152-165, https://doi.org/10.1108/IJM-05-2016-0104.

Reay, T., Jaskiewicz, P., \& Hinings, C. R. (Bob). (2015). How Family, Business, and Community Logics Shape Family Firm Behavior and "Rules of the Game" in an Organizational Field. Family Business Review, 28(4), 292-311. https://doi.org/10.1177/0894486515577513

Venter, H.G. (2017). Self-Transcendence: Maslow's Answer to Cultural Closeness. Journal of Innovation Management. Journal or Innovation and Management. 4 (2016): 3-7

Weber, M. (1927). General Economic History. Glencoe, IL: Free Press, 1950.

Westoff, C.F. Frejka, T. (2007). Religiousness and Fertility among European Muslims. Population and Development Review. (33)4 785-809. https://doi.org/10.1111/j.1728-4457.2007.00197.x 


\section{Biographies}

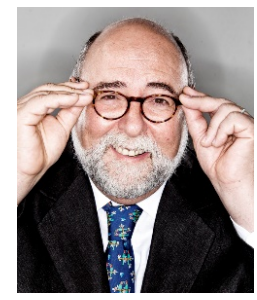

Alfredo Behrens. Behrens, A. Montevideo, Uruguay, 1951. He is also a Brazilian national and holds a Ph.D. granted by the University of Cambridge, U.K. in 1983. He worked on economic development until 2000, having lectured on economic integration at Princeton University (1986-1989) and at Florida State University until 1992, when he joined the World Bank to work on economies in transition. In 2000 he was visiting research fellow at the London Business School, transitioning then to working on cross-cultural management issues. On extended sabbatical from FIA Business School, São Paulo, Brazil, Dr. Behrens currently lectures on Cross-cultural Leadership at the Global MBA with IME Business School, at the Universidad de Salamanca, Spain, where his also coordinates the Soft Skills area at the said MBA and is a member of the advisory council of the Global Studies Think Tank. He published Culture and Management in the Americas at Stanford University Press (2009) and Gaucho Dialogues, with Anthem Press (2018) when, by ILBA (CA) the book was selected to be taken to TV Series. His most recent article is A Pig in a Poke Management, published by Thunderbird International Review (2020) and his most recent book is one for children, entitled Teresa Voa, published by Edições Esgotadas, Porto, 2020. http://www.alfredobehrens.com 